\title{
Teaching with Relevance: Saudi Students' Perceptions of a Foundation Course in Communication Skills
}

\author{
Philline M. Deraney \\ Imam Abdulrahman Bin Faisal University, Dammam, Saudi Arabia \\ https://orcid.org/0000-0001-8392-293X
}

\begin{abstract}
This study explores undergraduate students' perceptions of a foundation-year communication skills course at a large public university in Saudi Arabia from the aspects of perceived course effectiveness and relevance using a cross-sectional survey research design. The survey yielded scaled and short-answer responses, which were then analyzed using statistical and thematic analyses. The results revealed that firstyear undergraduate students $(n=209)$ in this study perceive communication skills as important for their future career and in major areas of their lives, and consider being a 'good' communicator as part of their cultural and religious heritage. Participants further define communication skills as predominantly an oral, information transfer that builds relationships with others from interpersonal and intercultural aspects. The findings also revealed disagreement and uncertainty about the communication course focus and requirement, relevance of course assignments and materials, and language of instruction. Recommendations for teaching communication skills with relevance in this context include explicit, focused communication instruction, studentcentered practical activities with cultural relevance, and, moving forward, coursework that integrates the communication discipline with the needs of the students' academic fields. Future research in this area could enhance teaching communication skills in the Saudi context and lead to more relevant instruction that could positively impact students in their professional lives.
\end{abstract}

Keywords: communication skills; culturally-relevant teaching; foundation year; Saudi Arabia

\section{Introduction}

Human communication in its varied forms is now omnipresent in undergraduate degree programs across the world. Communication has been offered as a social science discipline for decades and more recently as a skillset necessary for the 21st Century that promotes success in higher education study, enhances professionalism, and advances graduates' careers (Arkoudis \& Doughney, 2014; 
McLean, Shaban \& Murdoch-Eaten, 2011; Wyatt \& Nunn, 2019). Universities often offer communication skills in relation to other transferable skills that can be adapted to various disciplines and professional contexts (Arkoudis \& Kelly, 2016) such as teamwork, problem solving, leadership, and critical thinking. Communication skills are now commonly integrated throughout program curricula or offered as a stand-alone course or series of courses (Arkoudis \& Kelly, 2016; Rüttermann et al., 2017).

In the Kingdom of Saudi Arabia, communication skills are integrated within learning domains in the National Qualifications Framework (Education and Training National Evaluation Commission, 2020) and included as a graduate attribute at several national universities. Yet, as discussed in the literature and common to the teaching of communication, "communication skills have traditionally been situated as marginal to core teaching and learning practices in disciplinary contexts" (Arkoudis \& Kelly, 2016, p. 3). Regional studies have also shown that undergraduate and even graduate students lack experience and confidence in communication skills (Alofisan et al., 2016; McLean, Shaban \& Murdock-Eaton, 2011). Adding to the issue of confidence, students who are not proficient in English, the language of instruction in the Saudi and regional context in several fields including health, engineering, computer and administrative sciences (Nouraldeen \& Elyas, 2014), often struggle with communication skills and intercultural competencies in the language (Karolak \& Guta, 2015; McLean, Shaban, \& Murdock-Eaton, 2011).

Communication skills, as a course and content area, is still fairly new to Saudi Arabia, and research on the perceptions or effectiveness of communication instruction has been focused on individual teaching strategies or interventions (Arkoudis \& Kelly, 2016) or communication skills as a byproduct of English language teaching (Alrashidi \& Phan, 2015). It is unclear from the research in this context how students perceive communication skills instruction. Such research could shed more light on the subject through a focused lens, apart from other transferable skills, and possibly support improved instructional practice in communication skills for both instructors and students. In this study, the communication skills course was offered in the first-year foundation program of a large public university in Saudi Arabia. Although communication skills are integrated throughout program curricula, the course serves as an introduction to communication skills. This study aims to contribute to the limited research on the subject and bring communication skills as a content and instructional area into the forefront through students' perceptions (Ardoukis \& Kelly, 2016; Alofisan et al., 2016; Alotaibi \& Alsaeedi, 2016; Havril, 2015; Karolak \& Guta, 2015; McLean, Shaban \& Murdoch-Eaten, 2011).

Research Question: Thus, this study uses a survey research design to explore one main question from two aspects: How do first-year undergraduate students perceive a communication skills course offered at a large, public Saudi university with regards to:

1) Course effectiveness on students' communication skills?

2) Course relevance to students as individuals? 


\section{Related Literature}

To frame the study, communication skills in higher education, relevance in relation to teaching communication skills, and the study context are discussed through literature related to the Gulf region in the Middle East.

\subsection{Communication skills in higher education}

Communication skills in higher education, defined as "oral and written communication skills aligned with professional, academic and community standards" (Ardoukis \& Kelly, 2016, p. 3), are recognized as a highly-desired skillset for 21st Century university graduates. As shown in various research studies, there is no definitive approach to teaching or assessing communication skills either globally or regionally (Alofisan et al., 2016; Ardoukis \& Kelly, 2016; Wyatt \& Nunn, 2019). Some academic programs include elements of interpersonal, business, and intercultural communication within one course. In other instances, communication skills are woven throughout the curriculum as a part of the discipline or as a series of courses (Karolak \& Guta, 2015). In some programs, a basic communication skills course is offered as an introductory course in students' first year (Arkoudis \& Kelly, 2016; Munz \& Colvin, 2018) with communication skills then integrated throughout the remainder of the students' curriculum. The latter represents the communication course approach in this study's context.

Beyond the basic definition of 'oral and written communication' as desired competencies, there are various communication aspects to be considered under the scope of communication skills that include communicating with confidence, non-verbal "gestures, facial expressions, body posture, and use of space" (Bonvillain, 2003, p. 35), and intercultural communication considerations. Munz and Colvin's (2018) study in a basic communication course found that students had communication apprehension or anxiety in situations of "real or anticipated communication" (McCroskey, 2001, p. 40) related to cultural identity factors including perceived language proficiency, possible judgment by peers, and religious affiliation. The authors concluded that the diversity of the students should be supported pedagogically through more informal interactions and activities related to their identities in the communication classroom.

Regionally, McLean, Shaban and Murdoch-Eaten (2011) studied the development of general skills over a one-year period in a first-year medical program in United Arab Emirates (UAE). The authors found that students' experiences with communication skills improved over the year though they were still not sufficiently confident in their skills, partially due to their perceived English language proficiency and lack of practice. From a pedagogical perspective, the authors suggested that "opportunities for practice of transferable skills should be identified in the curriculum" (p. e297) to improve students' experience and confidence, and the purpose of such courses should be "articulated as important for future practice and should be assessed" (p. e297). Similarly, Wyatt and Nunn (2019) studied a community of practice in teaching communication skills to engineering students through project-based learning in UAE and concur with regional and international studies (Noblitt, Vance \& Depoy Smith, 2010) that 
found that student-centered, practical approaches, such as project-based learning and case studies, improve team, oral and non-verbal communication skills.

English-language scholar Al-Seghayer (2015) argued that communicative competence is being taught only minimally in the Saudi context, and urged instructors to use student-centered techniques such as discussions, interviews, and role plays to promote communication skills and the ability to interpret meaning in discourse. The author suggested that educators should "equip their students with techniques they could employ in the case of a communication breakdown" (p. 90) to support more meaningful communication instruction.

Alofisan et al. (2016) found that the vast majority (95\%) of Saudi pediatric residents in hospitals across the Kingdom believed that learning communication skills was crucial and that medical students should be taught effective communication skills for strong patient-doctor relationships (93\%). Yet, only 39\% reported having communication skill training available to them and even fewer felt highly confident in their communication skills, similar to other regional studies mentioned. The authors concluded that communication skills training should be integrated into the residents' curriculum.

Similarly, Alotaibi and Alsaeedi (2016) studied medical students' attitudes toward communication skills in Taif University (western Saudi Arabia). The researchers found that medical students believed that communication skills were important for future doctors who would need to communicate well and respectfully with patients. The study also revealed that more advanced students (level 5) had a more positive attitude than students earlier in their academic career (level 2).

\subsection{Communication skills and teaching with relevance}

Building on Ladson-Billings (2013) concept of culturally-relevant pedagogy, Gay (2010) defines culturally responsive teaching as "using the cultural knowledge, prior experiences, frames of reference, and performance styles of ethnically diverse students to make learning encounters more relevant and effective" (p. 31) including examples, materials, and other references that are relevant to the students as individuals. Bassey (2016) also posits that educators who employ "a culturally responsive method in their teaching see culture as a strength which can be used effectively to enhance academic and social achievement" (p. 1) and promote equitable education, in which culture is a valued asset. Thus, cultural relevance in relation to communication skills is important as effective and meaningful communication skills rely on implicit and explicit cultural knowledge and experiences through different channels (e.g., oral, written, non-verbal).

Further emphasizing the importance of communication and teaching with relevance in the Saudi context, Nouraldeen and Elyas (2014), in support of Kramsch's (1998) work, posit that culture, language and communication are related from various aspects as people use "spoken, written or visual means to create meaning...reflect their attitudes, beliefs, and point of view" and as a "symbol of their social identity" (Nouraldeen \& Elyas, 2014, p. 64). As English is considered a global language (Crystal, 2003) and the language of communication 
in many scientific disciplines in the Arab world (Zughoul, 2003), communication skills in English are relevant to students in this context. Further, these skills in English are viewed as instrumental for students' future, personally and professionally in particular (Alrashidi \& Khan, 2015; Elyas, 2008). In AlSeghayer's (2011) seminal work on teaching English in Saudi Arabia, the author emphasizes how the English language has been and still is an important tool for obtaining and advancing careers, international business activities, flexible access to global knowledge, and understanding of and between as a "link language" ( $\mathrm{p}$. 13) to other cultures, i.e., a means of intercultural communication.

Yet, as recognized by Nouraldeen and Elyas (2014) and international scholars (McLean, Shaban, \& Murdoch-Eaton, 2011; Munz \& Colvin, 2018), there are other factors to be considered when teaching communication skills, not only the language of instruction. Nouraldeen and Elyas (2014), in their study on cultural factors that affect learning English, discuss communication and its relationship to the Islamic culture, which, the authors argue, is synonymous with Saudi culture. In agreement with Al Haq and Smadi's (1996) earlier work, the authors posit that Islam encourages communication through different languages to spread the faith, increase knowledge, and enhance communication with people from other cultures. The research also found that while Saudi students communicate in the English language for instrumental purposes (i.e., as a function to work/study in international/intercultural contexts), Arabic is often preferred to communicate within conversations, within the culture, at the interpersonal level (both oral and written), as part of cultural identity, i.e., Arabic is their 'mother tongue' that offers fluent conversation and understanding.

As many faculty members in Saudi higher education are expatriates and students study/travel abroad (Al-Seghayer, 2011), intercultural communication patterns for Saudi students are increasingly dynamic. Havril (2015), who studied Saudi university students' intercultural competence at Jazan University (southwest Saudi Arabia), concluded that intercultural competence, both in positive and negative experiences, is needed in progressively multicultural environments. "If the participants of intercultural situations experience more positive and negative, upward and downward dimensions, in the end, they can really become interculturally competent in our culture-convergent world" (Havril, 2015, p. 565).

Karolak and Guta (2015) also studied communication patterns between students and their international instructors from the students' perspective in Saudi higher education. The authors discussed the complexities of understanding nonverbal cues, such as head nodding or lack of response, not necessarily as unwillingness to communicate or passive participation but as not fully understanding the utterance. These complexities can cause miscommunication and/or communication avoidance and, ultimately, the authors recommended teaching considerations and approaches that are culturally-relevant. The authors recommended explicit instruction to deal with communication uncertainty, clear focused objectives and assignments, and debates to ensure students know how to represent their points of view. In concurrence with studies previously mentioned, Karolak and Guta (2015) concluded that intercultural competences such as 
empathy, tolerance, "patience, flexibility, suspending judgment" (p. 52) are needed for Saudi students' futures in an increasingly globalized workforce.

\subsection{Communication skills course in the study context}

The context for this study was a communication skills course offered in the firstyear program of a large public university in Saudi Arabia. As per the current practice in Saudi higher education, students take a foundation year to prepare for study in their discipline. The communication skills course is part of a series of general courses including English as a Foreign Language (EFL), mathematics, natural sciences, computer education, and related supporting studies. Although communication skills are integrated throughout the curriculum as required by the National Qualifications Framework, this course serves as an introductory, standalone course in the foundation year. The course medium of instruction, the lecture notes/booklet, presentations, and the vast majority of resources, including videos and course links, are in the English language, and the course is gender-segregated as per the Saudi cultural norm for undergraduate students. Course lecture notes and presentations include a few scattered references to the Saudi culture when referring to non-verbal communication such as eye contact/gestures and the mention of communication as positive speech and good manners in the Islamic tradition. This course, a supporting course to prepare students for better communication in their prospective colleges, has been offered since 2015 and averages over 20 sections with 20-25 students (average) in each section.

The course focuses on nine communication skills topics: communication principles, channels of communication distinguishing verbal and non-verbal communication, intro to field-specific communication (health, computer science, etc.), barriers to communication, communication self-awareness, presentation skills (including basic paralinguistic elements of vocal variety and prosody), professional/work communication, and teamwork. Topics are covered weekly, a total of 28 instructional hours, and the main assignments associated with these topics are graded role plays, a group project consisting of a multi-media presentation (speeches with visual), and two written assignments (resume and skills assessment) along with quizzes/final as assessments. Throughout the weekly interactive lectures, several activities such as case studies for communication, spontaneous role plays, and discussion prompts are included. The weekly lectures are also standardized for the faculty members through shared presentations prepared by the department.

\section{Methodology}

\subsection{Research Design}

To explore the research question of the communication course's perceived effect on communication skills and relevance, this study employed a cross-sectional, online survey design in which data were collected from first-year students enrolled in the introductory communication skills course. This design was chosen as surveys provide a "description of trends, attitudes, or opinions of population by studying a sample" (Creswell, 2014, p. 155) and for ease of participation, particularly during the COVID-19 pandemic and consequent online instruction. The survey was distributed in April 2020 (primarily via social media applications and learning platforms) and completed anonymously in April-May by first-year 
students who were enrolled in the communication skills course in the 2019-2020 academic year. The two-part survey design measured students' perceptions trends in scaled items (quantitative) with regards to course effectiveness and course relevance and explored their perceptions further in open-ended shortanswer questions (qualitative).

\subsection{Participants}

Of the 225 participants, 16 responses were removed from the data due to incomplete or unrelated responses. The final sample analyzed consisted of 209 Saudi nationals (ages 17-20) in the first year of a foundation year program, in a large, public university as shown in Table 1. Although a convenience sample, participants represented seven different sections of communication skills taught by six different instructors.

Table 1. Participant demographics $(n=209)$.

\begin{tabular}{|c|c|c|c|}
\hline & & Frequency & $\%$ \\
\hline \multirow{2}{*}{ Gender } & Male & 82 & 39.2 \\
\hline & Female & 127 & 60.8 \\
\hline \multirow{4}{*}{$\begin{array}{c}\text { Prospective } \\
\text { College }\end{array}$} & Health & 120 & 57.4 \\
\hline & $\begin{array}{c}\text { Computer } \\
\text { Science/Information } \\
\text { Technology }\end{array}$ & 42 & 20.1 \\
\hline & Business & 35 & 16.7 \\
\hline & No response/other & 12 & 5.7 \\
\hline
\end{tabular}

\subsection{Instrument}

The online instrument was created and piloted specifically for this study to answer the question not only of perceived course effectiveness, but also the issue of cultural relevance in this context. To ensure content validity, five bilingual experts with doctorates and extensive experience in teaching in Saudi Arabia and the Gulf region reviewed and offered feedback on the survey. An expert in educational evaluation and measurement provided feedback on the scale and direction of the items for clarity and ease of completion. A professor in curriculum and pedagogy revised the curriculum/course materials survey items while a third expert in educational psychology offered perspective on varying the survey into scaled and short-answer questions to gather more meaningful data. A fourth expert with a doctorate in English reviewed the language for enhanced meaning, and, finally, a communication professor examined the scope of the items in relation to the communication skills course and concept. Further, the researcher has academic background in the communication discipline and has taught various communication skills courses in Saudi Arabia for several years.

After the initial review and feedback to ensure content validity (Creswell, 2014), three items were removed for lack of clarity, leading or repetitive questions, and six of the questions were rewritten. The survey was then piloted further with four current undergraduate students all who had taken communication skills within the past two years to review content and clarity of questions and language. Based on the student feedback, the visual format was changed for easy use on various 
devices and one question was slightly changed to provide further clarity. Within one week of the survey distribution, the researcher also discussed the survey (questions and format) with another bilingual instructor and two students who had completed the survey for further feedback. At that point, after review of the instrument by five experts, one colleague, and six students, no changes or revisions were suggested.

The resultant 19-item survey (see Appendix 1) consisted of 12 scaled items on a 4point Likert scale from strongly disagree (1) to strongly agree (4) and seven shortanswer questions to allow participants to express their perceptions and add more explanatory data to the research design (Creswell, 2013). Cronbach's Alpha was used to measure instrument reliability on the scaled items and found to be 896 showing high internal consistency (Nunnally \& Bernstein, 1994). The validity of the internal consistency of the scaled items was verified by calculating the Pearson correlation coefficient between the scores for each item and the aspect studied (course effectiveness and relevance) and found to be internally consistent as shown in Appendix 1.

The data of the scaled-item responses were found to have a moderately leftskewed, non-normal distribution with a skewness of -.506 $(\mathrm{SE}=.168)$ and kurtosis of $.015(\mathrm{SE}=.335)$; Shapiro-Wilk test: $\mathrm{W}(209)=.972, \mathrm{p}=.00)$. The central limit theorem in statistics states that in large samples $(>30)$, data distribution tends to be normal, regardless of the shape of the data, and parametric tests can be used (Field, 2013; LaMorte, 2016; Zahediasl \& Ghasemi, 2012). In addition, the seven qualitative short-answer questions further supported and expanded upon the scaled items. For the descriptive data, mean ranges were categorized to interpret and analyze the data trends at equal intervals (.75): 4.00-3.28 (Strongly Agree); 3.27-2.52 (Agree); 2.51-1.76 (Disagree); 1.75-1.00 (Strongly Disagree).

\subsection{Data analysis}

As the survey consisted of two forms of data, scaled survey and short-answer responses, two analyses, both quantitative and qualitative, were completed. For the scaled-survey items, descriptive and inferential statistical analyses were conducted considering frequency, percentages, and the variables of gender and prospective college via an independent sample t-test and one-way ANOVA. For the short-answer responses, qualitative analysis, including coding responses and identifying recurring patterns in the data (Creswell, 2013), was performed to inductively explore participants' perceptions on the communication course and its relevance to the students. Based on the recurring patterns, common themes emerged, which were then rechecked with the data and aligned with the scaled items to answer the research questions, as shown in the results. Thus, the scaled survey items measuring effectiveness and relevance were corroborated and supported with qualitative short-answer responses. In reporting the qualitative responses, the participants' exact quotes were used for authenticity of data.

\section{Results}

Overall, first-year students enrolled in an introductory communication skills course perceived that the course had positive effects on their communication skills and relevance to them as individuals $(\mathrm{M}=2.81$; $\mathrm{SD}=.579)$. As further shown in 
Table 2 and the students' short-answer responses, students ranked their understanding of the concepts of communication/communication skills higher than the relevance of the course to them as students. Using statistical analyses to explore key variables of participants' gender and prospective college $(\alpha=0.05)$, an independent sample t-test revealed that there was no statistically significant difference in student perception of the communication course based on gender (female $\mathrm{M}=2.89 ; \mathrm{SD}=.55 ;$ male $\mathrm{M}=2.74 ; \mathrm{SD}=.64 ; \mathrm{T}=1.875 ; \alpha=.063$ ). A oneway ANOVA analysis on the variable of prospective college also indicated no statistical significance $(F=1.294 ; a=.274)$ on students' perceptions of the communication course. It was shown, however, that IT and business-track students $(\mathrm{M}=2.86 ; \mathrm{SD}=.52$ and $\mathrm{M}=2.84 ; \mathrm{SD}=.53$ respectively) perceived the communication course slightly more positively, followed by the health-track students $(\mathrm{M}=2.79 ; \mathrm{SD}=.60)$.

Table 2. Students' perceptions of the communication skills course $(n=209)$.

\begin{tabular}{|c|c|c|c|c|}
\hline & Mean & SD & General trend & Rank \\
\hline Course Effect on Communication Skills & 2.91 & 0.590 & Agree & 1 \\
\hline Course Relevance to Participants & 2.60 & 0.695 & Agree & 2 \\
\hline Overall & 2.81 & 0.579 & \multicolumn{2}{|c|}{ Agree } \\
\hline
\end{tabular}

\subsection{Communication course effectiveness}

Of the 10 survey items (eight scaled and two short-answer) directly concerned with the aspect of course effectiveness on communication skills, participants agreed that communication was important in their lives and that the course had a positive effect on their communication skills $(\mathrm{M}=2.91$; $\mathrm{SD}=.590)$. As shown in Table 3, the majority of participants $(85 \%)$ perceived communication skills as important 'for my future career' $(\mathrm{M}=3.29$; $\mathrm{SD}=.891)$. Similarly, nearly $87 \%$ of participants responded that 'communication is used in all major areas of life' (M $=3.25 ; \mathrm{SD}=.794)$.

At the lowest end of the item rankings, there was division on participants' responses about whether the course should be required $(\mathrm{M}=2.46$; $\mathrm{SD}=.938$ ); half of participants $(50.2 \%)$ responded that the course should not be required and nearly the same number (49.8\%) agreed it should be a required course.

Table 3. Descriptive statistics of communication skills course effectiveness.

\begin{tabular}{|c|c|c|c|c|c|c|c|c|c|}
\hline \multirow{2}{*}{\multicolumn{2}{|c|}{ Items }} & \multicolumn{4}{|c|}{ Scale } & \multirow{2}{*}{$\mathbf{M}$} & \multirow[b]{2}{*}{ SD } & \multirow{2}{*}{ Rank } & \multirow{2}{*}{$\begin{array}{c}\text { Response } \\
\text { Trend }\end{array}$} \\
\hline & & $\begin{array}{l}\text { Strongly } \\
\text { disagree }\end{array}$ & Disagree & Agree & $\begin{array}{l}\text { Strongly } \\
\text { agree }\end{array}$ & & & & \\
\hline \multirow{2}{*}{$\begin{array}{l}\text { Communication } \\
\text { skills are } \\
\text { important for my } \\
\text { future career. }\end{array}$} & $\mathrm{N}$ & 15 & 16 & 71 & 107 & \multirow{2}{*}{3.29} & \multirow{2}{*}{.891} & \multirow[b]{2}{*}{1} & \multirow[b]{2}{*}{$\begin{array}{c}\text { Strongly } \\
\text { agree }\end{array}$} \\
\hline & $\%$ & 7.2 & 7.7 & 34.0 & 51.2 & & & & \\
\hline
\end{tabular}




\begin{tabular}{|c|c|c|c|c|c|c|c|c|c|}
\hline \multirow{2}{*}{$\begin{array}{l}\text { Communication is } \\
\text { used in all major } \\
\text { areas of life. }\end{array}$} & $\mathrm{N}$ & 9 & 19 & 92 & 89 & \multirow{2}{*}{3.25} & \multirow{2}{*}{.794} & \multirow[b]{2}{*}{2} & \multirow[b]{2}{*}{ Agree } \\
\hline & $\%$ & 4.3 & 9.1 & 44.0 & 42.6 & & & & \\
\hline \multirow{2}{*}{$\begin{array}{l}\text { The skills learned } \\
\text { in this course will } \\
\text { help me in my } \\
\text { other courses. }\end{array}$} & $\mathrm{N}$ & 17 & 37 & 110 & 45 & \multirow{2}{*}{2.88} & \multirow[b]{2}{*}{.840} & \multirow[b]{2}{*}{5} & \multirow[b]{2}{*}{ Agree } \\
\hline & $\%$ & 8.1 & 17.7 & 52.6 & 21.5 & & & & \\
\hline \multirow{2}{*}{$\begin{array}{l}\text { Communication } \\
\text { skills should be a } \\
\text { required course. }\end{array}$} & $\mathrm{N}$ & 37 & 68 & 75 & 29 & \multirow{2}{*}{2.46} & \multirow{2}{*}{.938} & \multirow[b]{2}{*}{8} & \multirow[b]{2}{*}{ Disagree } \\
\hline & $\%$ & 17.7 & 32.5 & 35.9 & 13.9 & & & & \\
\hline \multirow{2}{*}{$\begin{array}{l}\text { This course } \\
\text { helped me } \\
\text { understand } \\
\text { myself more as a } \\
\text { communicator. }\end{array}$} & $\mathrm{N}$ & 22 & 62 & 97 & 28 & \multirow[b]{2}{*}{2.63} & \multirow[b]{2}{*}{.846} & \multirow[b]{2}{*}{6} & \multirow[b]{2}{*}{ Agree } \\
\hline & $\%$ & 10.5 & 29.7 & 46.4 & 13.4 & & & & \\
\hline \multirow{2}{*}{$\begin{array}{l}\text { I communicate } \\
\text { better with my } \\
\text { classmates/peers } \\
\text { after this course. }\end{array}$} & $\mathrm{N}$ & 23 & 75 & 81 & 30 & \multirow[b]{2}{*}{2.56} & \multirow[b]{2}{*}{.870} & \multirow[b]{2}{*}{7} & \multirow[b]{2}{*}{ Agree } \\
\hline & $\%$ & 11.0 & 35.9 & 38.8 & 14.4 & & & & \\
\hline \multirow{2}{*}{$\begin{array}{l}\text { If I apply good } \\
\text { communication } \\
\text { skills, I will be a } \\
\text { better person for } \\
\text { myself and for } \\
\text { others. }\end{array}$} & $\mathrm{N}$ & 9 & 23 & 107 & 70 & \multirow[b]{2}{*}{3.14} & \multirow[b]{2}{*}{.755} & \multirow[b]{2}{*}{3} & \multirow[b]{2}{*}{ Agree } \\
\hline & $\%$ & 4.3 & 11.0 & 51.2 & 33.5 & & & & \\
\hline \multirow{2}{*}{$\begin{array}{l}\text { Diversity } \\
\text { (different } \\
\text { viewpoints) } \\
\text { improves } \\
\text { communication } \\
\text { skills. }\end{array}$} & $\mathrm{N}$ & 10 & 34 & 103 & 62 & \multirow[b]{2}{*}{3.04} & \multirow[b]{2}{*}{.808} & & \multirow[b]{2}{*}{ Agree } \\
\hline & $\%$ & 4.8 & 16.3 & 49.3 & 29.7 & & & 4 & \\
\hline \multicolumn{6}{|c|}{ Course Effect on Communication Skills } & 2.91 & 0.590 & \multicolumn{2}{|c|}{ Agree } \\
\hline
\end{tabular}

To further explore perceptions of the communication skills course, participants were also asked 'what communication skills were learned or improved in the course' and 'after taking the course, define communication skills' in short-answer responses (See Appendix 1). Two consistent themes emerged from the shortanswer data in this area: 1) communication as a skill for information transfer, and 2) communication skills to build relationships and understand others.

\subsubsection{Communication skills as information transfer}

The majority of student participants (about 69\%) defined communication as a direct transfer of information from sender to receiver or between people in one form or another for a direct purpose; communication as a 'way' or 'process to send and receive messages', to 'give and take messages,' or to communicate for a purpose such as to inform:

Sending and receiving signals from a sender to a receptor for a certain reason or goal. (health-track student)

Communication is sending information, feelings, thoughts, ideas and work through some channels like social media or talking or gesturing to someone. (computer science student) 
In congruence with the definition of communication for a direct, focused purpose or as information transmission, a large percentage of the participants, about $60 \%$, mentioned presentation, sometimes referred to as 'talking' or 'speaking,' and nonverbal communication as the skills most improved or learned in the course. These skills, as reported by students, focus on the 'how' of direct communication:

When someone speaks to you, you should see him [eye contact]. And don't give him your back. (health-track student)

Maintaining better face [facial] gestures. (computer science student)

Speaking, presentation, and non-verbal communication skills. (several similar responses)

\subsubsection{Communication skills to build relationships and understand others}

The second major theme in students' responses when defining communication and learned/improved communication skills was communication skills to build relationships and understand others. Students discussed elements of empathy (rather than sympathy) and listening to other people's opinion for better understanding:

Communication is very important to understand the world, people, ideas, cultures, and everything; establish rapport and maintaining it. (several similar responses)

Set of skills that enable and facilitate communication with different types of people, from different cultures and communities. (health-track student)

When responding about gained or improved communication skills, students $(40 \%)$ noted that the most important communication skills improved were related to building relationships and understanding others:

Empathy + accepting other people's opinion. (health-track student)

Reaching out [to others] to communicate/active listening. (business student)

\subsection{Communication course relevance}

To consider the communication skills course relevance to participants as individuals, the survey questions, four scaled and four short-answer, focused on students' perceptions of the language of instruction, curriculum/materials relevance including from an Arab/Islamic perspective, and practical applications (i.e., assignments and activities).

As illustrated in Table 4, students, as a general trend, slightly agreed that the course book and materials were relevant to them as individuals, deepened their understanding of the concept, and improved their experience $(\mathrm{M}=2.60 ; \mathrm{SD}=.695)$. The highest ranking in this aspect was related to the course material improving students' learning experience $(\mathrm{M}=2.70 ; \mathrm{SD}=.837)$. However, participants disagreed that the assignments helped them 'become a better communicator' (M $=2.45 ; \mathrm{SD}=.935$ ) with $19 \%$ of students strongly disagreeing on this item. 
Table 4. Descriptive statistics of communication course relevance.

\begin{tabular}{|c|c|c|c|c|c|c|c|c|c|}
\hline \multirow{2}{*}{ Related Items } & & \multicolumn{4}{|c|}{ Scale } & \multirow{4}{*}{$\begin{array}{l}\mathbf{M} \\
2.62 \\
\end{array}$} & \multirow{4}{*}{$\begin{array}{l}\text { SD } \\
\\
.864\end{array}$} & \multirow{4}{*}{$\begin{array}{c}\text { Rank } \\
\\
3\end{array}$} & \multirow{4}{*}{$\begin{array}{l}\begin{array}{l}\text { Response } \\
\text { Trend }\end{array} \\
\text { Agree }\end{array}$} \\
\hline & & $\begin{array}{l}\text { Strongly } \\
\text { disagree }\end{array}$ & $\begin{array}{l}\text { Dis- } \\
\text { agree }\end{array}$ & Agree & $\begin{array}{l}\text { Strongly } \\
\text { agree }\end{array}$ & & & & \\
\hline \multirow{2}{*}{$\begin{array}{l}\text { The course book } \\
\text { and materials } \\
\text { deepened my } \\
\text { understanding } \\
\text { of } \\
\text { communication. }\end{array}$} & $\mathrm{N}$ & 27 & 52 & 104 & 26 & & & & \\
\hline & $\%$ & 12.9 & 24.9 & 49.8 & 12.4 & & & & \\
\hline \multirow{2}{*}{$\begin{array}{l}\text { The course } \\
\text { material } \\
\text { improved my } \\
\text { learning } \\
\text { experience. }\end{array}$} & $\mathrm{N}$ & 20 & 53 & 105 & 31 & \multirow{2}{*}{2.70} & \multirow{2}{*}{.837} & \multirow[b]{2}{*}{1} & \multirow[b]{2}{*}{ Agree } \\
\hline & $\%$ & 9.6 & 25.4 & 50.2 & 14.8 & & & & \\
\hline \multirow{2}{*}{$\begin{array}{l}\text { The course } \\
\text { material was } \\
\text { related to me as } \\
\text { a person; I could } \\
\text { identify with it. }\end{array}$} & $\mathrm{N}$ & 15 & 67 & 103 & 24 & \multirow[b]{2}{*}{2.65} & \multirow[b]{2}{*}{.777} & \multirow[b]{2}{*}{2} & \multirow[b]{2}{*}{ Agree } \\
\hline & $\%$ & 7.2 & 32.1 & 49.3 & 11.5 & & & & \\
\hline \multirow{2}{*}{$\begin{array}{l}\text { Overall, the } \\
\text { assignments } \\
\text { helped me } \\
\text { become a better } \\
\text { communicator. }\end{array}$} & $\mathrm{N}$ & 40 & 60 & 84 & 25 & \multirow[b]{2}{*}{2.45} & \multirow[b]{2}{*}{.935} & \multirow[b]{2}{*}{4} & \multirow[b]{2}{*}{ Disagree } \\
\hline & $\%$ & 19.1 & 28.7 & 40.2 & 12.0 & & & & \\
\hline \multicolumn{6}{|c|}{ Course Relevance } & 2.60 & 695 & \multicolumn{2}{|c|}{ Agree } \\
\hline
\end{tabular}

Participants were also asked short-answer questions to explore their perceptions of the course relevance to them as individuals: 'Should the course be taught in English or Arabic,' 'Were the course book, materials, and examples related to the Saudi/Arab or Islamic culture?' 'Which assignments or activities improved your communication skills the most and the least' (See Appendix 1). For each question, students were asked to briefly explain their responses. Three main themes emerged from the short-answer data: 1) relevance of language of instruction; 2) communication skills linked to religious/cultural heritage and intercultural communication; and, 3) relevance of oral communication activities.

\subsubsection{Relevance of language of instruction}

Students' short-answer responses showed uncertainty about the language of instruction - whether communication skills should be taught in their professional language of English or native language of Arabic. A slight majority of the students indicated that the course should be taught in English (53\%), others recommended Arabic (25\%), and a third group suggested both languages to offer students a choice $(22 \%)$. Noteworthy to mention, the question did not suggest instruction in both languages as an option; nevertheless, several students added the response. The majority of explanations for those who preferred the course in English focused on English as a global or professional language needed for their coursework: 
English, it is the universal language (used by most countries); In English because almost all of our future study depends on [the] language. (several similar responses)

English, because English has become the main language. But that doesn't mean that people should ignore Arabic communication skills. (healthtrack student)

Arabic was mentioned as the 'mother tongue' to be used within the culture (intracultural) and in interpersonal situations for better expression and also considering issues of language proficiency; students take a separate English language course simultaneously with the communication skills course. A sizeable third group of participants suggested that the course should be offered in both languages, perhaps bilingually, to further benefit students:

Arabic, firstly because it's my native language. Secondly there are more Arabic speakers than English one in K.S.A. [Saudi Arabia]. Thirdly, Arabic is nearer to our hearts than English. There is a variety of vocabular in Arabic that lets us express our emotions better than English. (healthtrack student)

In my opinion I think it should be taught in both languages because our first language is Arabic, which will be used more in this country, but, also, we need to learn this course using English language because it is the global language. (computer science student)

\subsubsection{Relevance to students' heritage and intercultural communication}

The short-answer question regarding course materials/examples used and their relevance to Saudi culture (i.e., culturally-relevant pedagogy) offered the most varied responses in that students often replied with both yes/no or hesitant responses of "I think so" or "I don't know." Considering the diversity of responses to this question, the overarching pattern of the data suggested that communication skills are essential, no matter the course materials or examples, as part of the students' cultural and religious (Islamic) belief structure. In more detail, a slight majority of participants $(55 \%)$ perceived the course as a relevant because, as shown in their responses, being a good communicator is related to being a good Saudi Muslim.

Yes, because Islam wants people to be good communicators. (health-track student)

Yes, it is, because Islam religion / our culture encourages people to behave and communicate well with others. (several similar responses)

Another substantial number of participants (45\%) responded that the course materials and examples were not directly related to Saudi culture. However, several viewed the lack of relevance as an opportunity to improve their intercultural communication skills. A few perceived the lack of culturally relevant materials/examples as a course weakness.

It was a bit broad and it doesn't directly apply to the Islamic culture, which is GOOD. We need to know how to communicate with different people that aren't necessarily Muslims. (health-track student) 
Not at all, but in a general way, yes, good communication skills to adapt with others. (business student)

There were no explicit examples of our culture in the material. It certainly would've been a more engaging experience if there were such examples. (healthtrack student)

\subsubsection{Relevance of oral activities/communication}

The large majority of participants (89\%) mentioned oral activities and assignments as related to their improvement of communication skills with only $11 \%$ mentioning the writing activities. Of the oral activities, in-class discussions and group work/group activities, in-class role plays were mentioned $48 \%$ of the time by participants (including elements of non-verbal communication such as facial gestures and body language). These activities were mentioned more often than the formal assignments of role plays and presentations (41\%). Students also mentioned oral activities as practicing their skills for the future and improving self-confidence and self-awareness in their explanations:

Presentations and in-class discussions; it is a practical application for what we learned, and we will need these skills in [the] future; because these actions make me more confident. (several similar responses)

$n$-class discussions because it is a practical training of the most common communication method which is face- to-face conversations. (healthtrack student)

Further, to the question of course improvements, most responses were general; however, nearly one-third of students $(29 \%)$ made recommendations related to both course effectiveness and course relevance scaled-survey items in their responses. Several students indicated that the course should be "non-graded, not obligatory," "as a discussion course," and use "more relevant and relatable examples," "more related to our needs," and "something we can use" with "more practical assignments." Some students mentioned that the main purpose of the communication skills course should be clarified.

\section{Discussion}

First-year university students in this study affirmed the positive role of communication skills in their current lives and future $(\mathrm{M}=2.91$, as shown in Table 3) and, to a lesser degree, course relevance to them as individuals ( $M=2.60$, illustrated in Table 4). Participants responded that communication skills were important for their lives and careers, and diversity of viewpoints improves communication (all above 3.0/4.0). However, scaled and short-answer responses related to the communication skills course were not as decisive (below 3.0), which is explored in the following discussion.

In the short-answer responses, participants defined communication skills as predominantly an oral (89\%), information transfer $(69 \%)$ that builds relationships with others. While the introductory concept of communication was seemingly clear to students, a limited mention of written communication activities and assignments $(11 \%)$ illustrates that the students perceived oral communication as the most relevant form of communication in the course. A plausible reason for the 
focus on the oral mode is that students, as shown in their short-answer responses, perceived the spoken in-class activities including spontaneous role plays, discussions, and in-class presentations as more effective than the written assessments on improving their communication skills. As shown in Table 4, students disagreed $(M=2.45)$ that the overall assignments improved their communication skills. In other words, students, as suggested by regional studies (Al-Seghayer, 2011; Karolak \& Guta, 2015; McLean, Shaban \& Murdoch-Eaton, 2011) found practical, in-class communication activities more effective and relevant for improving their skills.

The most complex findings of this research are related to students' perceptions about the course relevance. Students' responses were divided regarding language of instruction and indecisive about the relevance of course material to Saudi/ Arab culture. English as the language of instruction was supported by just over half of participants while $47 \%$ either suggested the course should be taught in Arabic or both English and Arabic. The primary reasons were related to the fact that English is the language of their future professional careers while for several participants, Arabic, as their 'mother tongue,' is preferred for increased understanding and communication. Several students also mentioned practicing English through the communication course while others felt it was hard to understand the communication concepts in English. This highlights the language proficiency concern reiterated in other studies (McLean, Shaban, \& Murdoch-Eaton, 2011; Munz \& Colvin, 2018). The implication here is that the language of instruction should be considered in relation to course purpose, benefit to academic programs and students, and students' current language proficiency level.

Regarding course material relevance, scaled-item responses showed slight student agreement about overall course relevance $(\mathrm{M}=2.60)$, but short-answer responses revealed considerable ambiguity about the cultural relevance of the course materials. In their explanations, students often began with words of uncertainty, "I don't know" or "I think so". Several mentioned, in concurrence with Nouraldeen and Elyas' (2014) research, that the relevance of the communication skills course was directly related to their Islamic heritage and upbringing which values and encourages strong and polite communication skills. However, a large number of students $(45 \%)$ perceived the course materials as not related, which several felt offered opportunities to learn and adapt to communication with those from other cultures. Thus, these students did not view the connection between intercultural communication and their own cultural context - the fact that intercultural communication and competence builds from their own culture. This concurs with Karolak and Guta's (2015) insight that some students may not be able to "grasp the specific aspects of culture in a consistent manner" (p. 51) particularly if students have not had extended experience with other cultures (Havril, 2015). A few astute students commented that explicit examples from the Saudi culture would have made the course more engaging and relatable. Unlike the point about language and communication skills, the majority of participants seemingly did not recognize the relationship between culture and communication skills (Bonvillain, 2003; Nouraldeen \& Elyas, 2014). This illustrates a missed pedagogical opportunity to connect communication skills and 
culture through culturally-relevant teaching and application of communication skills for students' future professional lives (Bassey, 2016). The indication then is that communication skills can explicitly support intercultural communication and still be clearly relevant and connected to the students' native culture.

Also related to the issue of relevance and course effectiveness was course status. Students' responses were divided about communication skills as a required course. Half of the participants disagreed about the course status as required and, in the open short-answer response about course improvements, nearly one-third of students mentioned that the course should be not required or non-graded, a discussion type course, or more relatable to be relevant. A plausible reason for this finding is related to Arkoudis and Kelly's (2016) critical discussion on the benefit of communication skills as part of an integrated disciplinary curriculum, not viewed as 'supplementary' by students. To illustrate, Alotaibi and Alsaeedi's (2016) study with Saudi medical students found that the highest-rated negative attitude scores toward learning communication skills were on the items "learning communication skills is too easy" and "communication skills teaching would have a better image if it sounded more like a science subject" (p. 794). Therefore, in agreement with the results of this study, students may perceive the communication skills subject as less important or relevant than other academic/scientific subjects, e.g., physics, biology, mathematics, or not directly related to their academic discipline. Although students agreed on the importance of communication skills $(\mathrm{M}=3.29)$ and mentioned aspects of the course that improved their skills, the necessity of the course as a foundation-year requirement was not clear to half of the students.

\section{Recommendations}

Based on the related literature and this study's findings, there are several possible recommendations for teaching communication skills with relevance. Firstly, the purpose and focus of the communication skills course should be clear to both faculty and students. Explicit instruction on the focus and goals of the course (e.g., oral, written, intercultural, or a concentrated combination) and related practical assignments will facilitate students' understanding of the course, its importance, and benefits. Focused instruction will further support the communication skills taught and, consequently, how these skills relate to and are used by students, i.e., how these skills are transferable to other academic and professional contexts.

As shown by this and previous studies-no matter the context, teaching interpersonal communication with relevance, considering culture, language, and related student factors is essential for communication. Communication, language, and culture are inextricably connected. Thus, communication skills instruction should reflect the nuances of the cultural context to be relevant. Examples, videos, and materials should reflect the student and his/her professional needs. Communication skills curricula can have a global focus and a myriad of concepts but should be adapted to respond to the context of the culture, the Saudi context in this case. Activities and assignments that are practical and culturally relevant, such as case studies and role plays, can benefit the students by highlighting the complexities of communication. Similarly, as evident in short-answer responses, 
the language of instruction matters to students. Thus, several factors should be considered regarding the language of instruction: purpose of the course/communication content, goals and language of the academic program, and students' language proficiency considering their stage in the program (early or advanced), and their ability to understand and communicate in the course language.

Finally, communication is a discipline in and of itself. Effective communication skills instruction should reflect relevant elements of the communication discipline and students' academic field. Thus, a co-constructed curriculum between discipline and communication experts/designers could ensure that disciplinespecific and general communication skills are negotiated, integrated, and assessed within the students' curriculum. As Arkoudis and Kelly (2016) affirmed, "The literature is unequivocal that high impact student learning occurs when communication skills are integrated within disciplinary learning and assessment" (p. 4). Moreover, in agreement with Karolak and Guta (2015), general and disciplinary professional development sessions on teaching communication skills in the Saudi context would support instruction and facilitate enhanced communication between faculty members and students.

As with all research, there are limitations and areas for improvement to expand on in future research. Exploration of communication skills courses from other Saudi universities and regions of the country with a larger sample is encouraged for more conclusive findings. Further, due to the nature of self-reporting, perceptions may be influenced by a variety of factors including understanding concepts, language proficiency, and the current COVID-19 pandemic and its implications on university study and coursework. A longitudinal study with more in-depth qualitative data could provide further insight into students' perceptions throughout their undergraduate study and more generalizable results related to the effectiveness of communication skills instruction over time.

\section{Conclusion}

This study aimed to explore undergraduate Saudi students' perceptions of a foundation-year communication skills course from the aspects of course effectiveness and relevance. The results indicated that the students in this study agreed that the course was effective in improving their communication skills and slightly agreed that the course was relevant to them as individuals, albeit with caveats. Students perceived the high importance of communication skills and viewed communication as primarily an oral, information transfer to build relationships with others. Participants also perceived in-class teaching and learning activities such as role plays, presentations, and discussions as effective for improving their communication skills. At the same time, a sizeable number of participants questioned the effectiveness and, primarily, the relevance of the course language of instruction, the relevance of course materials including examples and assignments, and communication skills as a requirement. In other words, the majority of participants perceived communication skills as highly important in their lives and future careers but were somewhat divided and 
uncertain about the relevance of the course to them as individuals and could not consistently link the communication skills course to their culture.

These findings, though on only a sample of students enrolled in communication skills, reveal a fertile pathway for future research and teaching with relevance. Further study could facilitate enhanced understanding of teaching communication skills in the Saudi context and lead to more relevant teaching and learning that would positively impact and benefit students in their careers and professional lives. As Saudi society becomes increasingly globalized, communication skills that are dynamic and adaptable are pertinent to advance knowledge and bring positive intercultural and intracultural exchange. Therefore, student-centered, relevant and explicit instruction is essential for deepened and evidenced impact on students' communication skills.

\section{Acknowledgement}

The author gratefully acknowledges the editors and reviewers for their valuable comments and insights, which significantly improved the manuscript.

\section{References}

Al Haq, F. A, \& Smadi, O. (1996). Spread of English and Westernization in Saudi Arabia. World Englishes, 15(3), 307-317. doi:10.1111/j.1467-971X.1996.tb00117.x

Alofisan, T., Al-Alaiyan, S., Al-Abdulsalam, M., Siddiqui, K. Hussain, I., \& Al-Qahtani, M. H. (2016). Communication skills in pediatric training program: National-based survey of residents' perspectives in Saudi Arabia. Journal of Family and Community Medicine, 23(1), 43-47. doi:10.4103/2230-8229.172233

Alotaibi, F. S., \& Alsaeedi, A. (2016). Attitudes of medical students toward communication skills learning in Western Saudi Arabia. Saudi Medical Journal, 37(7), 791-795. doi:10.15537/smj.2016.7.14331

Alrashidi, O., \& Phan, H. (2015). Education context and English teaching and learning in the Kingdom of Saudi Arabia: An overview. English Language Teaching, 8(5), 3344. doi:10.5539/elt.v8n5p33

Al-Seghayer, K. (2011). English teaching in Saudi Arabia: Status, issues, and challenges. Riyadh, Saudi Arabia: Hala Printed Co.

Al-Seghayer, K. (2015). Salient key features of actual English instructional practices in Saudi Arabia. English Language Teaching, 8(6), 89-99. doi:10.5539/elt.v8n6p89

Arkoudis, S. \& Doughney, L. (2014). Good practice report: English language proficiency. Sydney, Australia: Australian Government Office for Learning and Teaching. https://melbourne-

cshe.unimelb.edu.au/_data/assets/pdf_file/0004/1489162/GPR_English_lang uage_2014.pdf

Arkoudis, S., \& Kelly, P. (2016). Shifting the narrative: International students and communication skills in higher education. International Education Research Digest 8, 2-12. https://www.ieaa.org.au/documents/item/664

Bassey, M. O. (2016). Culturally responsive teaching: Implications for educational justice. Education Sciences, 6(35), 1-6. doi:10.3390/educsci6040035

Bonvillain, N. (2003). Language, culture, and communication: The meaning of messages (4th ed.). Upper Saddle River, NJ: Pearson Education, Inc.

Creswell, J. W. (2014). Research design: Qualitative, quantitative, and mixed methods approaches ( $4^{\text {th }}$ ed.). Thousand Oaks, CA: Sage Publications, Inc. 
Creswell, J. W. (2013). Qualitative inquiry \& research design: Choosing among five approaches ( $3^{\text {rd }}$ ed.). Thousand Oaks, CA: Sage Publications, Inc.

Crystal, D. (2003). English as a global language (2nd ed.). Cambridge, UK: Cambridge University Press.

Education and Training National Evaluation Commission. (2020). Alitar Alwatani lilmuahalaat [National Qualifications Framework]. Riyadh, Saudi Arabia: Education and Training National Evaluation Commission.

Elyas, T. (2008). The attitude and the impact of the American English as a global language within the Saudi education system. Novitas-ROYAL, 2(1), 28-48. http:// citeseerx.ist.psu.edu/viewdoc/summary?doi=10.1.1.557.9274

Field, A. (2013). Discovering statistics using IBM SPSS statistics (4th $\mathrm{ed}$ ). Thousand Oaks, CA: Sage Publications, Inc.

Gay, G. (2010). Culturally responsive teaching: Theory, research, and practice (2nd ed.). New York, NY: Teachers College Press.

Ghasemi, A., \& Zahediasl, S. (2012). Normality tests for statistical analysis: A guide for non-statisticians. International Journal of Endocrinology and Metabolism, 10(2), 486489. doi:10.5812/ijem.3505.

Havril. A. K. (2015). Improving intercultural competence of female university students in EFL within Saudi Arabia. Procedia - Social and Behavioral Sciences, 192, 554-566. doi:10.1016/j.sbspro.2015.06.091

Karolak, M., \& Guta, H. (2015). Intercultural communication in the context of Saudi Arab tertiary education. In Raddawi R. (eds.) Intercultural Communication with Arabs (4156). Springer, Singapore. https://doi.org/10.1007/978-981-287-254-8_4

Kramsch, C. J. (1998). Language and Culture. Oxford: Oxford University Press.

Ladson-Billings, G. (2013). The dreamkeepers: Successful teachers of African American children ( $2^{\text {nd }}$ ed.). San Francisco, CA: Jossey Bass.

LaMorte, W. W. (2016). Central limit theorem. Boston University School of Public Health. https://sphweb.bumc.bu.edu/otlt/MPH-

Modules/BS/BS704_Probability/BS704_Probability12.html

McCroskey, J. C. (2001). An introduction to rhetorical communication. Boston, MA: Allyn \& Bacon.

McLean, M., Shaban, S., \& Murdoch-Eaten, D. (2011). Transferable skills of incoming medical students and their development over the first academic year: The United Arab Emirates experience. Medical Teacher, 33, 297-305. doi:10.3109/0142159X.2011.565826

Munz, S. M., \& Colvin, J. (2018). Communication apprehension: Understanding communication skills and cultural identity in the basic communication course. Basic Communication Course Annul, 30(10), 172-199. https://ecommons.udayton.edu/bcca/vol30/iss1/10

Noblitt, L., Vance, D. E., \& Depoy Smith, M. L. (2010). A comparison of case study and traditional teaching methods for improvement of oral communication and critical-thinking skills. Journal of College Science Teaching, 39(5), 26-32.

Nouraldeen, A. S., \& Elyas, T. (2014). Learning English in Saudi Arabia: A socio-cultural perspective. International Journal of English Language and Linguistics Research, 2(3), 56-78. http://eajournals.org/wp-content/uploads/Learning-English-in-SaudiArabia-A-Socio-Cultural-Perspective1.pdf

Nunnally, J. C., \& Bernstein, I. H. (1994). Psychometric theory (3rd ed.). New York: McGrawHill.

Rüttermann, S., Sobotta, A., Hahn, P., Kiessling, C., \& Härtl, A. (2017). Teaching and assessment of communication skills in undergraduate dental education - a survey 
in German speaking countries. European Journal of Dental Education, 21, 151-158. https://doi.org/10.1111/eje.12194

Wyatt, M., \& Nunn, R. (2019). Tracing the growth of a community of practice centered on holistic project-based learning in communication at an engineering university in the United Arab Emirates: Insights from a socially-situated teacher cognition perspective. Forum Qualitative Sozialforschung / Forum: Qualitative Social Research, 20(2), Article 8. doi:10.17169/fqs-20.2.3170

Zughoul, M. R. (2003, May). Globalization and EFL/ESL pedagogy in the Arab world [Conference presentation]. 23rd Annual Convention of the Moroccan Association of Teachers of English (MATE), Fez, Morocco. https:/ / files.eric.ed.gov/fulltext/ED479810.pdf

\section{Appendix 1}

\section{Communication Skills Course Survey Scaled Items}

\begin{tabular}{|l|l|l|l|}
\hline & \multicolumn{1}{|c|}{ Course Effectiveness } & \multicolumn{1}{|c|}{$\begin{array}{c}\text { Correlation } \\
\text { Coefficient }\end{array}$} & Significance \\
\hline 1. & $\begin{array}{l}\text { Communication skills are important for my } \\
\text { future career. }\end{array}$ & $0.858^{* *}$ & 0.000 \\
\hline 2. & $\begin{array}{l}\text { Communication is used in all major areas of } \\
\text { life. }\end{array}$ & $0.887^{* *}$ & 0.000 \\
\hline 3. & $\begin{array}{l}\text { The skills learned in this course will help me in } \\
\text { my other courses. }\end{array}$ & $0.897^{* *}$ & 0.000 \\
\hline 4. & $\begin{array}{l}\text { Communication skills should be a required } \\
\text { course. }\end{array}$ & $0.628^{* *}$ & 0.000 \\
\hline 5. & $\begin{array}{l}\text { This course helped me understand myself more } \\
\text { as a communicator. }\end{array}$ & $0.816^{* *}$ & 0.000 \\
\hline 6. & $\begin{array}{l}\text { I communicate better with my classmates/ peers } \\
\text { after this course. }\end{array}$ & $0.827^{* *}$ & 0.000 \\
\hline 7. & $\begin{array}{l}\text { If I apply good communication skills, I will be a } \\
\text { better person for myself and for others. }\end{array}$ & $0.768^{* *}$ & 0.000 \\
\hline 8. & $\begin{array}{l}\text { Diversity (different viewpoints) improves } \\
\text { communication skills. }\end{array}$ & $0.706^{* *}$ & 0.000 \\
\hline
\end{tabular}

\begin{tabular}{|c|l|l|l|}
\hline & Course Relevance Items & $\begin{array}{l}\text { Correlation } \\
\text { Coefficient }\end{array}$ & Significance \\
\hline 9. & $\begin{array}{l}\text { The course book and materials deepened my } \\
\text { understanding of communication. }\end{array}$ & $0.774^{* *}$ & 0.000 \\
\hline 10. & $\begin{array}{l}\text { The course material improved my learning } \\
\text { experience. }\end{array}$ & $0.929^{* *}$ & 0.000 \\
\hline 11. & $\begin{array}{l}\text { The course material was related to me as a } \\
\text { person; I could identify with it. }\end{array}$ & $0.523^{* *}$ & 0.000 \\
\hline 12. & $\begin{array}{l}\text { Overall, the assignments helped me become a } \\
\text { better communicator. }\end{array}$ & $0.790^{* *}$ & 0.000 \\
\hline
\end{tabular}

${ }^{* *}$ Correlation is significant at the 0.01 level (2-tailed). 


\section{Survey Short-Answer Items}

13. Should the course be taught in English or Arabic? Please explain your answer.

14. Were the course book, materials, and examples related to the Saudi/Arab or Islamic culture? Why or why not?

15. Which assignments or activities improved your communication skills the most? How?

16. Which assignments or activities improved your communication skills the least? Why?

17. After taking the course, define communication skills.

18. What communication skills were learned or improved in the course?

19. How would you improve the course (if applicable)? 